Article

\title{
Urban Food Sources and the Challenges of Food Availability According to the Brazilian Dietary Guidelines Recommendations
}

\author{
Camila Aparecida Borges ${ }^{1, * \mathbb{D}}$, William Cabral-Miranda ${ }^{2}$ and Patricia Constante Jaime ${ }^{1}$ \\ 1 Department of Nutrition, School of Public Health, University of São Paulo, Avenue. Dr. Arnaldo 715, \\ 01246-904 São Paulo-SP, Brazil; constant@usp.br \\ 2 Faculty of Philosophy, Letters and Human Scienc-es, University of São Paulo, Street do Lago 717, \\ 05508-900 São Paulo-SP, Brazil; williamcabral@usp.br \\ * Correspondence: camilaborges.usp@gmail.com; Tel.: +55-113-0617-701
}

Received: 31 October 2018; Accepted: 30 November 2018; Published: 6 December 2018

\begin{abstract}
The study investigated availability and food sources in urban areas using elements of the NOVA food classification system, adopted by the Brazilian Dietary Guidelines, in a Brazilian municipality. In addition, the study also aimed to identify inequalities in the geographical distribution of food retailers that commercialize healthy and/or unhealthy foods. This cross-sectional study was performed in the municipality of Jundiai in the State of São Paulo, Brazil. Data from within-store audit and geographic data were used to characterizing the nutrition community environment. The mean was calculated for food items available in each of the four NOVA groups for each audited food retailer. The mean of food items available in each of the four NOVA groups for each audited food retail were calculated. The density and proportion of different types of food retailers were georeferenced. The supermarkets, medium market stores, and grocery stores presented the highest availability of unprocessed foods as well as ultra-processed foods. Establishments that sold primarily unprocessed foods and included a fruits and vegetables section at the entrance of the store had a greater availability of healthy foods, but their density in the territory was low compared to establishments that prioritized the sale of ultra-processed foods and sold ultra-processed foods in the checkout area. Especially in middle- and low-income areas, the concentration of food retailers with priority sale of ultra-processed products is reaches 22 times higher than the sale of unprocessed or minimally processed foods. The study supported the identification of regions where it was necessary to improve access to equipment that marketed unprocessed foods as a priority.
\end{abstract}

Keywords: food sources; food security; food deserts; urban food system; NOVA food classification system

\section{Introduction}

Evidence indicates that food environment influences food accessibility [1-3], diet quality [4-6], and even the occurrence of obesity [7-11]. Factors in the community food environment linked to healthy food consumption include the presence of food stores and access to them, the types of food retailers in the territory [4,12,13], availability (quality of food stores) [14], accessibility (hours of operation), affordability of healthy foods [15,16], product placement, and food advertising [17-19].

The growing literature on the associations between food environment and obesity has been constantly explored in the context of "food deserts", a term which has been used, more specifically, to refer to areas with low access to adequate food at affordable prices, which can contribute to social disparities in the diet and have a negative impact on the health of the population [2]. The relation with obesity has been greatly investigated, since food deserts are environments that, paradoxically, 
may encourage excessive caloric consumption [2]. Another important concept that has emerged in food-environment studies is the "food swamp", which involves relative amounts of different types of foods (e.g., an assessment of energy-dense foods swamping out healthier options) and/or retail establishments [20].

In the food environment, most specifically in the community nutrition environment, it is possible to identify several types of food retailers such as supermarkets, wholesalers, grocery stores, convenience stores, confectioners, coffee shops, bars, restaurants, bakeries, among others [21]. These food retailers play a key role in the food choices and health of individuals, since they can offer healthy food varieties as well as ultra-processed foods $[4,8,12,19]$. The lack of food retailers near households and workplaces and the availability of unhealthy foods in these places can hinder access to a balanced diet $[5,22-24]$. A previous study conducted in the city of Jundiai, São Paulo, using secondary data showed higher concentrations of small markets in relation to supermarkets in lower-income neighborhoods. In addition, food retailers that sold fresh and unprocessed foods, such as farmers' markets and butchers, were more present in the central areas of the city [25].

Both the access to various food retail services and the types of food they sell can become significant environmental barriers for vulnerable populations to achieving food security [1]. The high prevalence of obesity among low-income populations has been related to the restricted access of these populations to healthy foods, as well as to the increasing density of fast-food and convenience stores in the food environment where they live $[1,8,10,11]$.

The greater supply of unprocessed foods (i.e., fruits, vegetables, cereals, fresh meat, eggs, milk) in food retail environments such as supermarkets and farmers' markets has a significant influence on food consumption, especially among low-income people [4,6]. In Brazil, a study conducted by Duran et al. [4] showed that living in the vicinity of supermarkets, grocery stores, and farmers' markets that commercialize fresh and unprocessed foods led to their consumption. On the other hand, the same study showed that living near food retailers that had a greater variety of sugary drinks and ultra-processed foods also increased the prevalence of their consumption.

Knowing the role played by the food environment, especially the community food environment, in the access to a healthier diet, and the fact that areas known as food deserts put food security at risk, thereby contributing to the increased obesity in the surrounding populations, the main goal of this study was to investigate availability and food sources in urban areas using the elements of the NOVA food classification system, adopted by the Brazilian Dietary Guidelines (BDG), in a Brazilian municipality. In addition, the study also aimed to identify inequalities in the geographical distribution of food retailers that commercialize healthy and/or unhealthy foods.

\section{Materials and Methods}

This cross-sectional study was performed in the municipality of Jundiai in the State of São Paulo, Brazil. According to the Brazilian Institute of Geography and Statistics (IBGE), the municipality has approximately 414,810 inhabitants (in 2018) with a Human Development Index (HDI) of 0.82, total area of 431,207 km [2], 686 census tracts (urban and rural), and its territory is divided into 74 neighborhoods according to the municipality's master plan. The average per capita income of the municipality in the rural area is $R \$ 643$ and in the urban area is $R \$ 925$. The city of Jundiai has $95.7 \%$ of its population residing in urban areas. This study is part of the research project "Interventions in the food retail environment: Overcoming the information obstacle for the promotion of adequate and healthy food habits in a municipality of the State of São Paulo", approved by the Ethics Committee of the Faculty of Public Health—protocol number 69045917.5.0000.5421.

To investigate the consumer nutrition environment and the community nutrition environment, an audit was carried out in the urban area of the municipality. Data collection began in December 2017 and ended in April 2018, totaling 573 of the 683 census tracts in the municipality, ensuring variability in audited aspects. A total of 650 food retailers were audited. In this process, a tool called "NOVA-based Audit of the Food Environment (AUDIT-NOVA)" was applied. Researchers were 
trained according to the protocol developed specifically for this research, containing information on approach, form fill, product specifications, and detailed explanations for each item to be audited in the food retail trade. This reliability and validation instrument measures aspects concerning food retailer types, availability, prices, food advertising, and number of food brands. The indicators present in the AUDIT-NOVA were based on the food classification proposed by Monteiro et al. [26] and called "NOVA", which classifies food into four groups according to the extent and purpose of its processing: 1. Unprocessed or minimally processed foods (i.e., fresh fruits and vegetables, meat, cereals, beans, fish, eggs, milk), 2. Processed culinary ingredients (i.e., salt, sugar, oil, butter, olive oil, animal fat), 3. Processed foods (i.e., canned vegetables and fruits, canned fish, dried meat, cheese, French bread), and 4. Ultra-processed foods (i.e., soft drinks, sweetened beverages, snacks, cookies, chocolates, sweets, instant noodles, breakfast cereals, milk drinks, and others).

All the establishments where the population could purchase food were audited. The identified commercial establishments were grouped into 13 major categories of retail establishments, as proposed by Costa et al. [13]: 1. Butchers and fish markets, 2. Central markets of fruits and vegetables, 3. Municipal markets of fruits and vegetables, 4. Private markets of fruits and vegetables, 5. Grocery stores, 6. Medium market stores (e.g., Carrefour Express, Dia Express), 7. Supermarkets/hypermarkets/wholesalers, 8. Bakeries, 9. Candy stores, 10. Convenience stores, 11.'Non-alcoholic beverage stores, 12. Pharmacies, food supplement stores, and 13. Others (pasta houses, cheese bread houses, houseware stores, cheese shops).

The AUDIT-NOVA contains a total of 66 foods and, in this study, these foods were categorized into four groups: 1. Unprocessed or minimally processed foods (orange, banana, papaya, apple, watermelon, tomato, onion, lettuce, carrot, zucchini, chayote, parsley and green onion, potato, cassava, corncob, eggs, prime beef, other beef, chicken, chicken breast, fish, cow's milk, beans, black beans, white rice, wheat flour, cassava flour, pasta, raw peanuts, water $500 \mathrm{~mL}$, water $5 \mathrm{~L}$ ), 2. Processed culinary ingredients (butter, soybean oil, olive oil, salt, refined sugar, granulated sugar), 3. Processed foods (dried meat, cheese, canned corn, tomato extract, canned sardines), and 4. Ultra-processed foods (dairy drink, noodles, seasoning, white bread, cornflakes, pizza, ice cream, soda can, soda $2 \mathrm{~L}$, light or diet soda, juices with added sugar, powdered beverage, corn snacks, chocolate cookies, candies, hot dog, sausage, bacon). The mean was calculated for food items available in each of the four NOVA groups for each audited food retailer, allowing the researchers to estimate the mean availability of unprocessed or minimally processed foods, processed culinary ingredients, processed foods, and ultra-processed foods.

The instrument also measures aspects of food availability according to NOVA, using indicators such as: availability of ultra-processed foods on checkout (yes or no); availability of fruits and vegetables at the entrance (yes or no); and whether the establishment commercializes mainly unprocessed or minimally processed foods (yes or no), processed culinary ingredients (yes or no), processed foods (yes or no), and ultra-processed foods (yes or no). Both "commercializes mainly unprocessed or minimally processed foods" and "commercializes mainly ultra-processed foods" were used in order to classify the establishments into healthy or unhealthy, respectively. Furthermore, availability of fruits and vegetables at the entrance (yes or no) and availability of ultra-processed foods on checkout (yes or no) were used as indicators of healthy and unhealthy food retailers, respectively.

This study combined the food environment audit data (carried out in commercial establishments) and the geographical measures. It was possible to identify the geographical coordinates of 643 of the 650 commercial establishments audited, with a loss of $1.08 \%$ of the sample. The geographical coordinates of longitude and latitude for each retail establishment were obtained using the Google Earth ${ }^{\circledR}$ computerized system. A geographic information system, ArcGIS 10.0 (Esri, CA, USA), and a digital cartographic base of the census tracts were used to geocode and determine the spatial location of stores. To calculate the density of healthy and unhealthy food retailer indicators among the inhabitants, it was considered that the resident population was living in households in the census tracts, available at the Demographic Census of IBGE (2010) [2]. In addition, the proportion of food retail trades with priority availability of ultra-processed foods was calculated based on the availability of unprocessed or 
minimally processed foods. Both the density of healthy and unhealthy food retailer and proportions were mapped together with the mean per capita income of each census tract. This mapping made it possible to verify social inequalities in the distribution of food retail trades around the municipality. To draw thematic maps, the technique of choroplethic representation was used.

To analyze the difference in mean food availability among the 13 types of retailers, Pearson's chi-square statistical tests were performed, due to the qualitative nature of the variable. To evaluate differences in the mean availability of unprocessed or minimally processed foods, culinary ingredients, processed foods, and ultra-processed foods according to the four indicators of healthy and unhealthy food retailers, mean comparison tests were used, because of the quantitative nature of the variable. Values of $p<0.05$ were considered statistically significant. The analyses were performed using the Stata 14 statistical program (Timberlake Analytics Software, TX, USA).

\section{Results}

In the process of auditing the food environment, it was possible to identify and geocode 643 food retail establishments used by the population to purchase food and then prepare it at home. The total amount of audited retailers was distributed as follows: $25.2 \%(n=164)$ grocery stores, $18.0 \%(n=116)$ pharmacies, food supplement stores, $14.3 \%(n=92)$ bakeries, $11.0 \%(n=71)$ candy stores, $7.6 \%(n=49)$ convenience stores, $5.9 \%(n=38)$ butchers and fish markets, 3.9\% $(n=25)$ non-alcoholic beverage stores, $3.6 \%(n=23)$ private markets of fruits and vegetables, $3.2 \%(n=21)$ other food retailers, $2.9 \%(n=18)$ supermarkets/hypermarkets/wholesalers, $2.0 \%(n=13)$ central markets of fruits and vegetables, $1.8 \%(n=12)$ medium market stores (i.e., Carrefour Express, Dia Express) and 0.3\% $(n=2)$ municipal markets of fruits and vegetables.

Table 1 shows the mean availability distribution of unprocessed foods, ingredients, processed foods, and ultra-processed foods according to retail types. Compared to other establishments, a higher availability of unprocessed foods was found in the supermarkets/hypermarkets/wholesalers, medium market stores (e.g., Carrefour Express, Dia Express), grocery stores, private markets of fruits and vegetables, central markets of fruits and vegetables, butchers and fish markets and municipal markets of fruits and vegetables $(p<0.05)$. As for the availability of culinary ingredients and processed foods, it was higher in medium market stores (e.g., Carrefour Express, Dia Express) and supermarkets/hypermarkets/wholesalers $(p<0.05)$. Finally, the availability of ultra-processed foods was higher in medium market stores (e.g., Carrefour Express, Dia Express), supermarkets/hypermarkets/wholesalers, grocery stores, bakeries, and convenience stores $(p<0.05)$.

The 643 commercial establishments were also grouped into four major categories according to the characteristics of the commercialized foods and indicators of healthy and unhealthy retailers in food environment. Unprocessed foods available in larger quantities than other food groups (Yes = 99 $(15.4 \%))$, ultra-processed foods available in larger quantities than other food groups (Yes $=560(87.1 \%))$, fresh fruits and vegetables located at the entrance of the store (Yes = $107(16.6 \%)$ ), and ultra-processed foods available in checkout areas (Yes $=568(88.3 \%)$ ). The number of retailers that prioritize the sale of ultra-processed foods is 5.6 times the number of retailers that primarily sell unprocessed foods.

Table 2 shows the distribution of the availability of unprocessed foods, ingredients, processed foods, and ultra-processed foods according to these four groups. It is possible to observe that the mean availability of unprocessed foods is higher in establishments that have unprocessed foods available in larger quantities than other food groups $(p<0.05)$, in the ones with a Fresh fruits and vegetables section near the entrance of the store $(p<0.001)$, but also in commercial establishments that have ultra-processed foods available in checkout areas. The highest mean availability of culinary ingredients and processed foods was found in establishments with a section of Fresh fruits and vegetables located near the entrance of the store $(p<0.001)$. Ultra-processed foods were available in all four groups; however, the highest availability of these foods was observed in establishments with a Fresh fruits and vegetables section $(p<0.001)$ and in establishments with the presence of ultra-processed foods available in checkout areas $(p<0.001)$. 
Table 1. Availability (mean and confidence interval) of unprocessed foods, culinary ingredients, processed foods, and ultra-processed foods according to types of food retailers. Jundiai-BRAZIL. 2017-2018.

\begin{tabular}{|c|c|c|c|c|c|c|c|c|}
\hline \multirow[t]{2}{*}{ Audited Food Retailers } & \multicolumn{2}{|c|}{$\begin{array}{l}\text { Availability of Unprocessed or } \\
\text { Minimally Processed Foods }\end{array}$} & \multicolumn{2}{|c|}{$\begin{array}{c}\text { Availability of } \\
\text { Culinary Ingredients }\end{array}$} & \multicolumn{2}{|c|}{$\begin{array}{c}\text { Availability of } \\
\text { Processed Foods }\end{array}$} & \multicolumn{2}{|c|}{$\begin{array}{c}\text { Availability of } \\
\text { Ultra-Processed Foods }\end{array}$} \\
\hline & Mean (CI) & $p^{*}$ & Mean (CI) & $p^{*}$ & Mean (CI) & $p^{*}$ & Mean (CI) & $p^{*}$ \\
\hline Butchers and fish markets & $8.2(6.3-10.1)$ & 0.000 & $1.5(1.0-2.0)$ & 0.000 & $2.5(1.9-3.0)$ & 0.000 & $6.4(5.0-7.8)$ & 0.000 \\
\hline Central markets of fruits and vegetables & $14.7(11.9-17.5)$ & & $0.8(0.0-1.5)$ & & $0.8(-0.0-1.6)$ & & $1.8(-0.5-4.1)$ & \\
\hline $\begin{array}{l}\text { Municipal markets of fruits } \\
\text { and vegetables }\end{array}$ & $5.5(4.5-6.5)$ & & 0 & & 0 & & 0 & \\
\hline Private markets of fruits and vegetables & $18.7(15.4-22.0)$ & & $2.3(1.5-3.1)$ & & $2.3(1.3-3.3)$ & & $7.3(4.6-10.0)$ & \\
\hline Grocery stores & $19.2(17.8-20.6)$ & & $3.8(3.6-4.0)$ & & $4.9(4.6-5.2)$ & & $13.3(12.7-14.0)$ & \\
\hline $\begin{array}{c}\text { Medium market stores (e.g., Carrefour } \\
\text { Express, Dia Express) }\end{array}$ & $27.7(22.4-33.0)$ & & $5.4(4.4-6.4)$ & & $6.2(5.1-7.4)$ & & $16.8(14.9-18.8)$ & \\
\hline Supermarkets/hypermarkets/wholesalers & $28.9(24.5-33.3)$ & & $5.2(4.3-6.0)$ & & $5.7(4.8-6.7)$ & & $16.8(15.4-18.1)$ & \\
\hline Bakeries & $4.7(3.9-5.5)$ & & $2.2(0.1-0.4)$ & & $3.1(2.9-3.4)$ & & $9.6(9.0-10.2)$ & \\
\hline Candy stores & $0.9(0.7-1.2)$ & & $0.2(0.1-0.4)$ & & $0.1(0.0-0.3)$ & & $3.9(3.0-4.7)$ & \\
\hline Convenience stores & $2.0(1.6-2.4)$ & & $1.1(0.7-1.4)$ & & $1.1(0.7-1.4)$ & & $8.6(7.8-9.4)$ & \\
\hline Non-alcoholic beverage stores & $1.7(1.3-2.1)$ & & $0.3(0.0-0.6)$ & & $0.1(0.0-0.3)$ & & $3.6(2.7-4.6)$ & \\
\hline Pharmacies, food supplement stores & $0.6(0.5-0.7)$ & & $0.0(0.0-0.2)$ & & 0 & & $1.9(1.6-2.3)$ & \\
\hline Others & $2.0(1.3-2.7)$ & & $0.6(0.1-1.0)$ & & $0.7(0.2-1.1)$ & & $6.2(5.0-7.5)$ & \\
\hline
\end{tabular}

* Pearson's chi-square, CI: confidence interval. Mean: mean of food items available. 
Table 2. Availability (mean and confidence interval) of unprocessed foods, culinary ingredients, processed foods, and ultra-processed foods according to healthy and unhealthy food retail. Jundiai-BRAZIL. 2017-2018.

\begin{tabular}{|c|c|c|c|c|c|c|c|c|}
\hline \multirow{2}{*}{ Healthy and Unhealthy Food Retail } & \multicolumn{2}{|c|}{$\begin{array}{l}\text { Availability of Unprocessed or } \\
\text { Minimally Processed Foods }\end{array}$} & \multicolumn{2}{|c|}{$\begin{array}{c}\text { Availability of } \\
\text { Culinary Ingredients }\end{array}$} & \multicolumn{2}{|c|}{$\begin{array}{l}\text { Availability of } \\
\text { Processed Foods }\end{array}$} & \multicolumn{2}{|c|}{$\begin{array}{c}\text { Availability of } \\
\text { Ultra-Processed Foods }\end{array}$} \\
\hline & Mean (CI) & $p^{*}$ & Mean (CI) & $p^{*}$ & Mean (CI) & $p^{*}$ & Mean $(\mathrm{CI})$ & $p^{*}$ \\
\hline \multicolumn{9}{|l|}{$\begin{array}{l}\text { Unprocessed foods or minimally } \\
\text { processed foods available in larger } \\
\text { quantities than other food groups }\end{array}$} \\
\hline Yes & $11.0(9.2-12.7)$ & 0.02 & $1.5(1.1-1.8)$ & 0.03 & $1.9(1.4-2.3)$ & 0.04 & $5.1(4.2-6.2)$ & 0.0000 \\
\hline No & $8.5(7.5-9.4)$ & & $1.9(1.8-2.1)$ & & $2.4(2.2-2.6)$ & & $8.5(8.0-9.0)$ & \\
\hline \multicolumn{9}{|l|}{$\begin{array}{l}\text { Ultra-processed foods available in larger } \\
\text { quantities than other food groups }\end{array}$} \\
\hline Yes & $9.1(8.2-9.7)$ & 0.18 & $2.0(1.8-2.2)$ & 0.0000 & $2.5(2.3-2.7)$ & 0.0000 & $8.7(8.2-9.1)$ & 0.0000 \\
\hline No & $7.4(5.8-9.0)$ & & $0.8(0.5-1.2)$ & & $1.2(0.9-1.6)$ & & $3.4(2.5-4.4)$ & \\
\hline \multicolumn{9}{|l|}{$\begin{array}{l}\text { Fresh fruits and vegetables located near } \\
\text { the entrance of the store }\end{array}$} \\
\hline Yes & $20.3(8.0-9.7)$ & 0.0000 & $3.2(2.8-3.6)$ & 0.0000 & $4.0(3.6-4.5)$ & 0.000 & $11.2(10.1-12.4)$ & 0.0000 \\
\hline No & $6.6(5.8-7.4)$ & & $1.6(1.4-1.8)$ & & $2.0(1.8-2.2)$ & & $7.3(6.9-7.8)$ & \\
\hline \multicolumn{9}{|l|}{$\begin{array}{l}\text { Ultra-processed foods available in } \\
\text { checkout areas }\end{array}$} \\
\hline Yes & $9.4(8.5-10.3)$ & 0.0002 & $2.1(1.9-2.2)$ & 0.0000 & $2.6(2.3-2.8)$ & 0.0000 & $8.8(8.3-9.3)$ & 0.0000 \\
\hline No & $4.6(3.3-5.9)$ & & $0.4(0.2-0.6)$ & & $0.6(0.3-0.8)$ & & $1.9(1.2-2.6)$ & \\
\hline
\end{tabular}

${ }^{*} t$ tests (mean comparison tests), CI: confidence interval. Mean: mean of food items available. 
Figure 1 shows the density of the four groups of commercial establishments classified according to the healthy and unhealthy food environment indicator in the municipality. In relation to unhealthy food environment indicators, which are ultra-processed foods available in larger quantities than other food groups and ultra-processed foods available in checkout areas, it was found that most areas have concentrations ranging from 3 to more than 40 establishments per 1000 inhabitants, that is, they are spread throughout the territory, especially among areas with middle and low per capita income. When analyzing the indicators of a healthy food environment such as unprocessed foods available in larger quantities than other food groups and fresh fruits and vegetables located near the entrance of the store, a smaller density of these establishments was observed in the municipality, showing mostly areas with a density lower than 3/1000 inhabitants. In areas of middle and low per capita income, it was possible to verify some areas with zero density of food retail trades that had unprocessed or minimally processed foods available in larger quantities than other food groups.

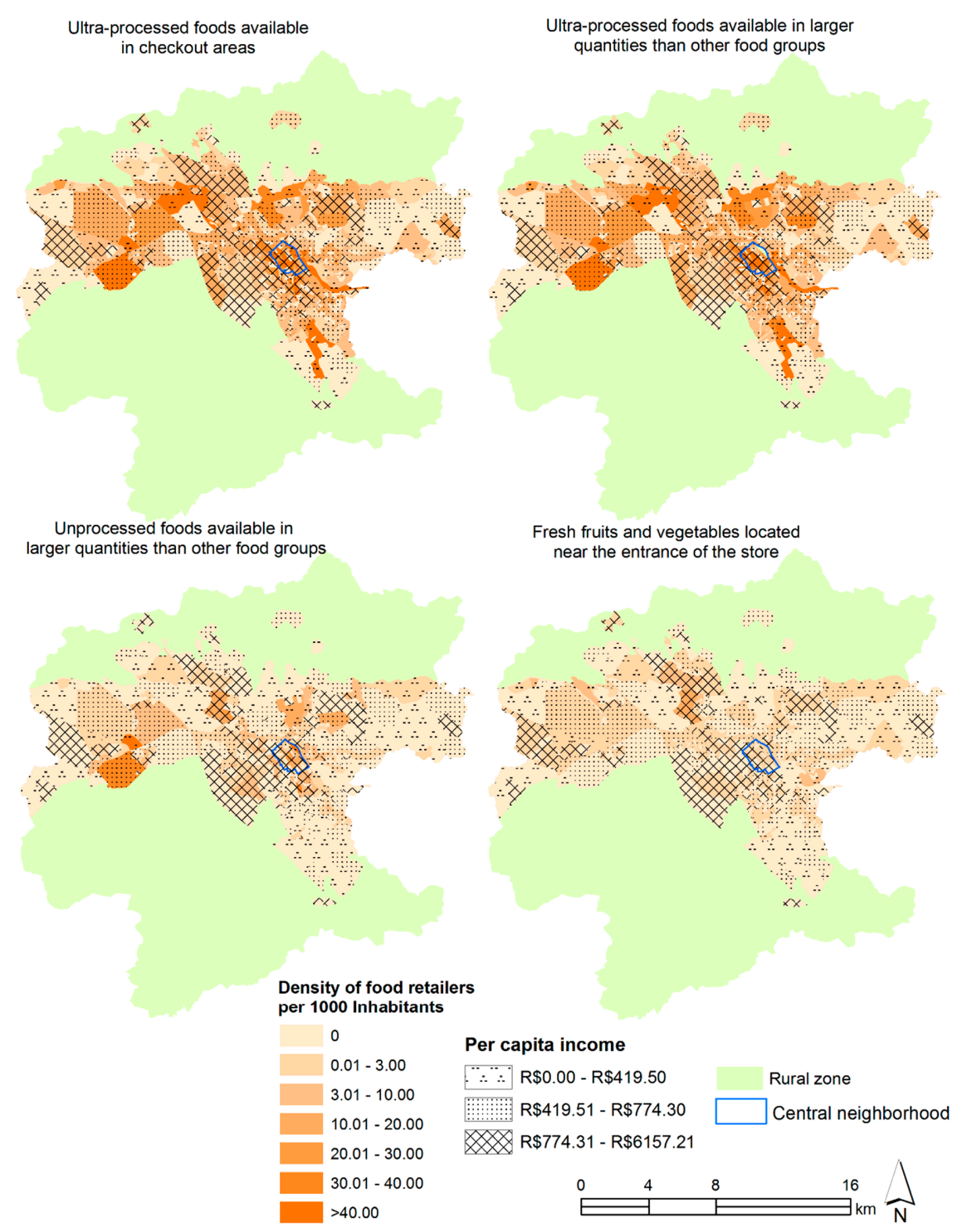

Figure 1. Density of healthy and unhealthy food retailers and per capita income in the municipality of Jundiai-BRAZIL. 2017-2018.

Figure 2 shows the proportion of food retail trades with priority availability of ultra-processed foods in relation to unprocessed and minimally processed foods. The highest proportions of food retail with priority availability of ultra-processed foods in relation to unprocessed or minimally processed 
foods are in low- and middle-income regions. In these areas, the concentration of food retailers with priority sale of ultra-processed products reaches 22 times higher than the sale of unprocessed or minimally processed products.

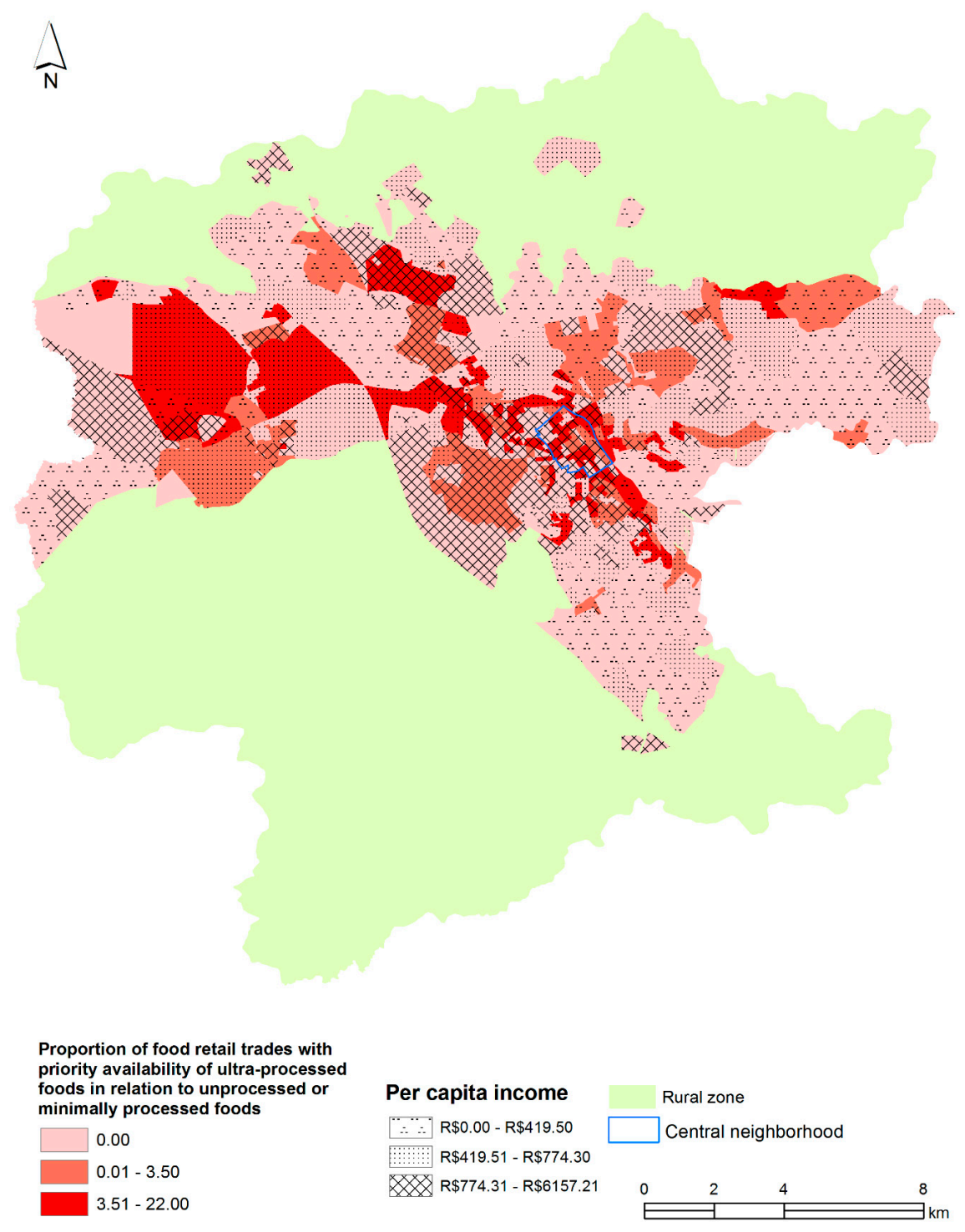

Figure 2. Proportion of food retail trades with priority availability of ultra-processed foods in relation to unprocessed or minimally processed foods and per capita income in the municipality of Jundiai-BRAZIL. 2017-2018.

\section{Discussion}

This study used cross-sectional data from an audit conducted in retail stores in the urban areas of a Brazilian municipality as well as geographic data in order to analyze food availability and spatial distribution of indicators of healthy and unhealthy food retailers in the municipality. Retail stores of the supermarkets/hypermarkets/wholesalers type, medium market stores (e.g., Carrefour Express, Dia Express), and grocery stores presented the highest availability of unprocessed foods as well as ultra-processed foods. When analyzing the distribution of healthy and unhealthy food environment indicators in the municipality according to socioeconomic indicators, establishments that sold primarily unprocessed foods and included a fruits and vegetables section near the entrance of the store had a greater availability of unprocessed foods, but their density in the territory was low, especially among 
middle- and low-income areas, when compared to establishments that prioritized the availability of ultra-processed foods.

The high proportion of food retail trades with priority availability of ultra-processed foods in relation to unprocessed and minimally processed foods, especially in middle- and low-income areas in the municipality, revealed areas of food deserts and food swamps [2] since access to healthy food was difficult. These areas may compromise the food security of the local population [23]. In addition, there is a potential in these areas for the population to consume larger quantities of ultra-processed foods and for a higher prevalence of obesity $[2,5,11]$. In Mexico, a study showed that excessive access and exposure to unhealthy foods and drinks, or "food swamps," may be of greater concern than food deserts in developing an obesity-prevention policy [22].

The retailers most frequently found in the municipality were grocery stores, pharmacies, food supplement stores, and bakeries which together added up 57\% of the audited retail trades. In this study, grocery stores displayed, at the same time, a high availability of unprocessed foods and a high availability of ultra-processed foods. In medium-sized municipalities such as Jundiai, bakeries are like mini-markets where locals often get some food products in addition to traditional baked goods. However, in general, these places sell mostly ultra-processed products, as seen in this study. The habit of buying food in places where there is a greater commercialization of ultra-processed foods favors their consumption and has a negative impact on nutrition [4]. A study using national and local data across the United States suggests that residents having low income, belonging to a minority, or living in rural neighborhoods are most often affected by poor access to supermarkets and healthy foods [3]. In this context, our study corroborates with these findings because it found a lower density of food retailers that sold healthy foods especially in low income neighborhoods.

In this study, a low proportion of trades was observed that sold primarily unprocessed or minimally processed foods in relation to ultra-processed foods, especially in middle- and low-income neighborhoods. The availability of healthy foods in a neighborhood has been associated with a higher consumption mainly of fruits and vegetables, which are unprocessed foods [6,27]. In Brazil, a study by Duran et al. [4] showed that the greater availability of fruits and vegetables in a neighborhood is associated with the regular consumption of these foods and, at the same time, living in places with few supermarkets and fresh-product markets reduces the consumption of these foods, mainly among the poorest inhabitants. In medium-sized municipalities like Jundiai, grocery stores are closer to individuals and facilitate the access to food, especially among people living in more peripheral neighborhoods [28,29]. Costa et al. [13] highlighted the role of small food retailers because of their wide variety of foodstuffs and geographical proximity to consumers, promoting a higher frequency of food purchases. However, these small supermarkets still need to improve the quality of the products they offer and the appearance of the stores, factors that can both potentially impact the food purchase decisions of low-income residents in particular [29].

The Brazilian Dietary Guidelines state the following golden rule: "always prefer unprocessed or minimally processed foods and freshly made dishes and meals to ultra-processed foods" [30]. In this case, in order for the population to respect this golden rule, food retailers must supply healthy foods. When verifying municipality areas having middle- and low-income populations with a high proportion of establishments that sold primarily ultra-processed food and at the same time with a low density of food retailers with availability of unprocessed food, we also verified the presence of the "supply" obstacle. According to the Brazilian Dietary Guidelines, the population should do the following to overcome this obstacle: "Shop mindfully. Avoid places that sell or serve mainly or only ultra-processed products. In supermarkets take and use a shopping list. Support farmers' markets, municipal markets, specialist retailers, and other places that sell varieties of natural and minimally processed foods, and prefer food produced by ecological methods" [30]. According to the findings of this study, the population in Jundiai-SP could have difficulties in overcoming the obstacle supply, especially middle- and low-income populations. 
When we analyzed the commercial establishments according to two indicators, namely, a large presence of unprocessed food and the presence of a fruits and vegetables section near the entrance of the store, we noticed that they were establishments with the highest mean values of unprocessed food availability in relation to those without these indicators. However, the density of establishments which prioritized unprocessed food sales and had a fruits and vegetables section near the entrance of the store were low compared to establishments that prioritized the sale of ultra-processed foods and sold ultra-processed foods in the checkout area. The inequality in the distribution of food retailers in the municipality could lead to the difficulty of access to healthier foods by the population. In another study carried out in the same municipality by our research group, but using secondary data, a lower density of retail trades was observed that sold fresh and unprocessed foods especially in peripheral neighborhoods [25]. In both studies, we identified that the population living in this municipality could face obstacles to achieving a healthy diet and following the recommendations of the Brazilian Dietary Guidelines [30].

Analyzing the geographic information, it is possible to say that some areas of the municipality are considered food swamps, or areas that have adequate access to healthy foods but are flooded with opportunities to consume calorie-dense foods and drinks [20]. The high density of establishments with the presence of ultra-processed foods in the checkout areas is worrying, because these types of foods, which are high in fat and sugar and poor in nutrients, and when they are present in these areas, stimulate impulse purchases and favor the increase of obesity, especially among children due to the products being close to their sight and height [31-33]. Food swamps are also choice environments laden with tempting stimuli and are therefore "hot" decision environments likely to prompt choices for immediate gratification [34].

Ultimately, this study showed the availability of unprocessed foods, culinary ingredients, processed foods, and ultra-processed foods in the audited food retailers in the municipality, showing that some socially vulnerable areas were more prone to enable the purchase of unhealthier products and that the city was flooded with opportunities to buy ultra-processed foods. The Brazilian Dietary Guidelines recommend that the population eat culinary preparations that are based on unprocessed or minimally processed foods and culinary ingredients [28]. In this context, the places in the municipality studied that can better support this practice are supermarkets/hypermarkets/wholesalers, medium market stores (e.g., Carrefour Express, Dia Express), grocery stores, private markets of fruits and vegetables, central markets of fruits and vegetables, butchers and fish markets, and municipal markets of fruits and vegetables, in addition to places where unprocessed foods are available in large quantities and where there are fresh fruits and vegetables located near the entrance of the store.

Author Contributions: Conceptualization, C.A.B.; Methodology, W.C.M.; Formal analysis, C.A.B. and W.C.M.; Investigation, C.A.B.; Writing—original draft, C.A.B.; Supervision, P.C.J.; Writing—review and editing, P.C.J.

Funding: The CAB was funded by the Foundation for Research Support of the State of São Paulo (FAPESP), protocol number 2016/12766-6.

Acknowledgments: The authors gratefully acknowledge the food retailers that allowed us to carry out the audit, Patricia Serafim for typing and organizing the data and also for her support with field researchers, Paulista University for the support during field collection, the researchers who worked on the data collection, the Foundation for Research Support of the State of São Paulo (FAPESP) for the post-doctoral scholarship provided to C.A.B., and Coordenação de Aperfeiçoamento de Pessoal de Nível Superior (CAPES) for the doctoral scholarship provided to W.C.M. The research reported in this article is granted by the International Development Research Centre (IDRC). The funders had no role in the study design, the data collection and analysis, the decision to publish, or the preparation of the manuscript.

Conflicts of Interest: The authors declare no conflict of interest. 


\section{References}

1. Zenk, S.N.; Schulz, A.J.; Israel, B.A.; James, S.A.; Bao, S.; Wilson, M.L. Neighborhood racial composition, neighborhood poverty, and the spatial accessibility of supermarkets in metropolitan Detroit. Am. J. Public Health 2005, 95, 660-667. [CrossRef] [PubMed]

2. Wrigley, N.; Warm, D.; Margetts, B.; Whelan, A. Assessing the Impact of Improved Retail Access on Diet in a "Food Desert": A Preliminary Report. Urban Stud. 2002, 39, 2061-2082. [CrossRef]

3. Larson, N.I.; Story, M.T.; Nelson, M.C. Neighborhood environments: Disparities in access to healthy foods in the U.S. Am. J. Prev. Med. 2009, 36, 74-81. [CrossRef] [PubMed]

4. Duran, A.C.; de Almeida, S.L.; Latorre, M.; Do, R.D.O.; Jaime, P.C. The role of the local retail food environment in fruit, vegetable and sugar-sweetened beverage consumption in Brazil. Public Health Nutr. 2016, 19, 1093-1102. [CrossRef] [PubMed]

5. Hager, E.R.; Cockerham, A.; O’Reilly, N.; Harrington, D.; Harding, J.; Hurley, K.M.; Black, M.M. Food swamps and food deserts in Baltimore City, MD, USA: Associations with dietary behaviours among urban adolescent girls. Public Health Nutr. 2017, 20, 2598-2607. [CrossRef] [PubMed]

6. Zenk, S.N.; Lachance, L.L.; Schulz, A.J.; Mentz, G.; Kannan, S.; Ridella, W. Neighborhood retail food environment and fruit and vegetable intake in a multiethnic urban population. Am. J. Health Promot. 2009, 23, 255-264. [CrossRef]

7. Galvez, M.P.; Hong, L.; Choi, E.; Liao, L.; Godbold, J.; Brenner, B. Childhood obesity and neighborhood food-store availability in an inner-city community. Acad. Pediatr. 2009, 9, 339-343. [CrossRef]

8. Gordon-Larsen, P. Food availability/convenience and obesity. Adv. Nutr. 2014, 5, 809-817. [CrossRef]

9. Sallis, J.F.; Glanz, K. Physical activity and food environments: Solutions to the obesity epidemic. Milbank Q. 2009, 87, 123-154. [CrossRef]

10. Van der Horst, K.; Oenema, A.; Ferreira, I.; Wendel-Vos, W.; Giskes, K.; van Lenthe, F.; Brug, J. A systematic review of environmental correlates of obesity-related dietary behaviors in youth. Health Educ. Res. 2007, 22, 203-226. [CrossRef]

11. Zenk, S.N.; Schulz, A.J.; Odoms-Young, A.M. How neighborhood environments contribute to obesity. Am. J. Nurs. 2009, 109, 61-64. [CrossRef] [PubMed]

12. Morland, K.; Diez Roux, A.V.; Wing, S. Supermarkets, other food stores, and obesity: The atherosclerosis risk in communities study. Am. J. Prev. Med. 2006, 30, 333-339. [CrossRef] [PubMed]

13. Costa, J.C.; Claro, R.M.; Martins, A.P.B.; Levy, R.B. Food purchasing sites. Repercussions for healthy eating. Appetite 2013, 70, 99-103. [CrossRef]

14. McDermot, D.; Igoe, B.; Stahre, M. Assessment of Healthy Food Availability in Washington State-Questioning the Food Desert Paradigm. J. Nutr. Educ. Behav. 2017, 49, 130-136. [CrossRef] [PubMed]

15. Thow, A.M.; Downs, S.; Jan, S. A systematic review of the effectiveness of food taxes and subsidies to improve diets: Understanding the recent evidence. Nutr. Rev. 2014, 72, 551-565. [CrossRef] [PubMed]

16. Claro, R.M.; Monteiro, C.A. Family income, food prices, and household purchases of fruits and vegetables in Brazil. Rev. Saude Publica 2010, 44, 1014-1020. [CrossRef] [PubMed]

17. Gamburzew, A.; Darcel, N.; Gazan, R.; Dubois, C.; Maillot, M.; Tomé, D.; Raffin, S.; Darmon, N. In-store marketing of inexpensive foods with good nutritional quality in disadvantaged neighborhoods: Increased awareness, understanding, and purchasing. Int. J. Behav. Nutr. Phys. Act. 2016, 13, 104. [CrossRef]

18. Liu, E.; Stephenson, T.; Houlihan, J.; Gustafson, A. Marketing Strategies to Encourage Rural Residents of High-Obesity Counties to Buy Fruits and Vegetables in Grocery Stores. Prev. Chronic Dis. 2017, 14, E94. [CrossRef]

19. Martinez, O.; Rodriguez, N.; Mercurio, A.; Bragg, M.; Elbel, B. Supermarket retailers' perspectives on healthy food retail strategies: In-depth interviews. BMC Public Health 2018, 18, 1019. [CrossRef]

20. Rose, D.; Bodor, J.N.; Swalm, C.M.; Rice, J.C.; Farley, T.A.; Hutchinson, P.L. Deserts in New Orleans? Illustrations of Urban Food Access and Implications for Policy; School of Public Health and Tropical Medicine Tulane, University New Orleans: Louisiana, LA, USA, 2009; p. 30.

21. Glanz, K.; Sallis, J.F.; Saelens, B.E.; Frank, L.D. Healthy nutrition environments: Concepts and measures. Am. J. Health Promot. 2005, 19, 330-333. [CrossRef]

22. Bridle-Fitzpatrick, S. Food deserts or food swamps? A mixed-methods study of local food environments in a Mexican city. Soc. Sci. Med. 2015, 142, 202-213. [CrossRef] [PubMed] 
23. Camp, N.L. Food insecurity and food deserts. Nurse Pract. 2015, 40, 32-36. [CrossRef] [PubMed]

24. Gordon, C.; Purciel-Hill, M.; Ghai, N.R.; Kaufman, L.; Graham, R.; Van Wye, G. Measuring food deserts in New York City's low-income neighborhoods. Health Place 2011, 17, 696-700. [CrossRef]

25. Fortes, M.F.; Borges, C.A.; Miranda, W.C.; de Jaime, P.C. Mapeando as desigualdades socioeconômicas na distribuição do comércio varejista local. Segurança Aliment. Nutr. 2018, 25, 45-58. [CrossRef]

26. Monteiro, C.; Cannon, G.; Levy, R.; Moubarac, J.; Jaime, P.; Martins, A. The star shines bright. J. World Public Health Nutr. Assoc. 2016, 7, 28-38.

27. Franco, M.; Diez Roux, A.V.; Glass, T.A.; Caballero, B.; Brancati, F.L. Neighborhood characteristics and availability of healthy foods in Baltimore. Am. J. Prev. Med. 2008, 35, 561-567. [CrossRef] [PubMed]

28. Cummins, S.; Flint, E.; Matthews, S.A. New neighborhood grocery store increased awareness of food access but did not alter dietary habits or obesity. Health Aff. (Millwood) 2014, 33, 283-291. [CrossRef] [PubMed]

29. Martin, K.S.; Ghosh, D.; Page, M.; Wolff, M.; McMinimee, K.; Zhang, M. What role do local grocery stores play in urban food environments? A case study of Hartford-Connecticut. PLoS ONE 2014, 9, e94033. [CrossRef] [PubMed]

30. Brazilian Dietary Guidelines/Ministry of Health of Brazil, Secretariat of Health Care, Primary Health Care Department; Monteiro, C.A., Translator; Ministry of Health of Brazil: Brasília, Brazil, 2015; 150p.

31. Chocolate at the checkout is a risk to public health. BMJ 2012, 345, e6921. Available online: https: / / www. ncbi.nlm.nih.gov/pubmed/23077365 (accessed on 30 October 2018). [CrossRef] [PubMed]

32. Cohen, D.A.; Babey, S.H. Candy at the cash register-A risk factor for obesity and chronic disease. N. Engl. J. Med. 2012, 367, 1381-1383. [CrossRef] [PubMed]

33. Campbell, S.; James, E.L.; Stacey, F.G.; Bowman, J.; Chapman, K.; Kelly, B. A mixed-method examination of food marketing directed towards children in Australian supermarkets. Health Promot. Int. 2014, 29, $267-277$. [CrossRef] [PubMed]

34. Yang, H.; Carmon, Z.; Kahn, B.; Malani, A.; Schwartz, J.; Volpp, K.; Wansink, B. The Hot-Cold Decision Triangle: A Framework for Healthier Choices. Mark. Lett. 2012, 23, 457-472. [CrossRef]

(C) 2018 by the authors. Licensee MDPI, Basel, Switzerland. This article is an open access article distributed under the terms and conditions of the Creative Commons Attribution (CC BY) license (http:/ / creativecommons.org/licenses/by/4.0/). 